\title{
原子系/連続体変換とナノスケール切削の 応力ひずみ解析*
}

\author{
稲村 豊四郎** 武 澤 伸 浩** 能 木 保 浩***
}

Atomic/Continuum Model Transformation and Its Application

to Stress-Strain Analysis of Nanoscale Cutting

Toyoshiro Inamura, Nobuhiro Takezawa and Yasuhiro Kumakl

A method by which to transform quantities of an atomic model to those of a continuum one, and vice versa has been proposed. The method is based on an idea that the displacement at a point in a continuum model should be a weighted mean of those of surrounding atoms in the corresponding atomic model, while stress values should have the inverse relation so as to preserve strain energy between the two models. The continuum model is then discretized by the Finite-Element Method so that matrix equations for the transformation are derived. These equations have been applied to the results of atomic-model-based simulation of nanoscale cutting to evaluate the stress and strain distributions in nanoscale cutting. The results show that the strain distribution is not very different from that of macroscale cutting but that there is almost no concentrated shear stress in the primary shear zone in nanoscale cutting.

Key words : atomic model, continuum model, FEM, stress, strain, nanoscale cutting

1. は じめに

最近，ナノスケール切削のメカニズムやき裂先端での力学現 象の解明などを目的として, 分子力学や分子動力学などの粒子

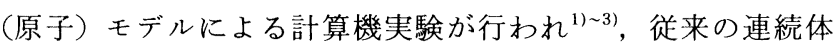
モデルによる解析では得られない新たな知見を我々に提供しつ つある.しかし一方で現実の固体の持つ原子個数に比べれば, これらの手法で扱える原子個数は極端に少ないから何らかの近 似法が必要であり，連続体モデルの中に局部微細観察を目的々 した粒子モデルを埋め込むなどの手法が要求される。をた超微 小切削について言えば，それがマク口切削とどのように違うか が問題であり，これを調べるためには超微小切削の応力やひず 又分布が必要になる。、いずれにしても粒子モデルと連続体モデ ル間で同じェネルギー原理が働くといら意味での力学量の等価 変換が鍵であり，これができて初めて前述の原子モデルの埋込 み ${ }^{4) 5)}$ が正しく行兄，また超微小切削の力学機構をマク口切削 のそれと比較するなどの新たな研究への道がひらかれる.

本研究では上記の等価変換の考方方とこれに基づく力学量の 具体的な算出法を提案し，更にこれを使ってナノスケール切削 の応力ひずみ解析を行う．提案する手法では応力を原子間力か ら，ひずみを原子変位から各々独立に算出でさるから，いわゆ る構成方程式の精度に左右されない応力分布が得られる.

\section{2. 力学量の等価変換}

\section{1 変 位}

原子系と連続体とを重ねた場合を想定すると，原子系の変位 は各原子の場所でのみ与えられるのに対し, 連続体の変位は原 子と原子のすきまでも存在する，これは原子変位の補間によっ て可能となるわけであり, 補間は平均化の一形態にほかならな い. 以下， 2 次元の場合を例に，これを数式表現する. い屯原

\footnotetext{
* 原稿受付 平成 5 年 5 月 6 日

** 正 会 員 名古屋工業大学 (名古屋市昭和区御器所町)

*** 学生会員 名古屋工業大学
}

子 $q$ の位置ベクトルを $\boldsymbol{r}_{q}=\left(x_{q}, y_{q}\right), q=1,2, \cdots$, 変位ベクト ルを $\boldsymbol{u}\left(\boldsymbol{r}_{q}\right)$ とし，位置ベクトル $\boldsymbol{r}_{p}=\left(x_{p}, y_{p}\right)$ に打ける連続体 の変位べクトル $\overline{\boldsymbol{u}}\left(\boldsymbol{r}_{p}\right)$ は， $\boldsymbol{r}_{p}$ を中心とする重み分布 $w\left(\boldsymbol{r}_{p}\right.$, $\left.\boldsymbol{r}_{q}\right)$ にって

$$
\overline{\boldsymbol{u}}\left(\boldsymbol{r}_{p}\right)=\int_{\Omega} w\left(\boldsymbol{r}_{p}, \boldsymbol{r}_{q}\right) \boldsymbol{u}\left(\boldsymbol{r}_{q}\right) \mathrm{d} \boldsymbol{r}_{q}=\sum_{q} w\left(\boldsymbol{r}_{p}, \boldsymbol{r}_{q}\right) \boldsymbol{u}\left(\boldsymbol{r}_{q}\right)
$$

の形で与えられるとする， $\Omega$ は平均化の範囲を表す．式 (1) で，原子がすべて同一の動きをしている場合は，対応する連続 体の変位もこれに等しくなければならないから，平均化の規模 にかかわらず

$$
\int_{\Omega} w\left(\boldsymbol{r}_{p}, \boldsymbol{r}_{q}\right) \mathrm{d} \boldsymbol{r}_{q}=\sum_{q} w\left(\boldsymbol{r}_{p}, \boldsymbol{r}_{q}\right)=1
$$

が要請される. 更に点 $\boldsymbol{r}_{p}$ での変位 $\overline{\boldsymbol{u}}\left(\boldsymbol{r}_{p}\right)$ に関与する点 $\boldsymbol{r}_{q}$ の 重みと，点 $\boldsymbol{r}_{q}$ での変位 $\overline{\boldsymbol{u}}\left(\boldsymbol{r}_{q}\right)$ に関与する点 $\boldsymbol{r}_{p}$ の重みとは等 しいとするのが妥当であるから

$$
w\left(\boldsymbol{r}_{p}, \boldsymbol{r}_{q}\right)=w\left(\boldsymbol{r}_{q}, \boldsymbol{r}_{p}\right)
$$

したがって

$$
\left.\begin{array}{c}
\frac{\partial}{\partial x_{p}} w\left(\boldsymbol{r}_{p}, \boldsymbol{r}_{q}\right)=\frac{\partial}{\partial x_{q}} w\left(\boldsymbol{r}_{q}, \boldsymbol{r}_{p}\right) \\
\frac{\partial}{\partial y_{p}} w\left(\boldsymbol{r}_{p}, \boldsymbol{r}_{q}\right)=\frac{\partial}{\partial y_{q}} w\left(\boldsymbol{r}_{q}, \boldsymbol{r}_{p}\right)
\end{array}\right\}
$$

が成り立つ. 重み分布の統計力学的な意味を後述の応力を使っ て付録 A に記すが，以下での重み分布は必ずしもこの意味に 限定しない。具体形としては

$$
w\left(\boldsymbol{r}_{p}, \boldsymbol{r}_{q}\right)=A \exp \left[-\frac{\left|\boldsymbol{r}_{p}-\boldsymbol{r}_{q}\right|^{2}}{2 \sigma^{2}}\right]
$$

を考えるたただし $A$ は条件式（2）を満たすよらに定める。 は平均化の範用を決めるパラメータであり， $\sigma$ が大なる程，連 続体変位や後述の応力ひずみ分布の詳細が消失する. また。 の下限値は原理的には付録 A の議論から定まる.

\section{2 ひずみ}

連続体変位を微分して求める. 原子の変位ベクトル $\boldsymbol{u}\left(\boldsymbol{r}_{q}\right)$ を $x, y$ 成分に分解したものを改めて $u\left(\boldsymbol{r}_{q}\right), v\left(\boldsymbol{r}_{q}\right)$ とすれば, 
ひずみの各成分は

$$
\begin{aligned}
\bar{\varepsilon}_{x}\left(\boldsymbol{r}_{p}\right) & =\sum_{q} \frac{\partial}{\partial x_{p}} w\left(\boldsymbol{r}_{p}, \boldsymbol{r}_{q}\right) u\left(\boldsymbol{r}_{q}\right) \\
\bar{\varepsilon}_{y}\left(\boldsymbol{r}_{p}\right) & =\sum_{q} \frac{\partial}{\partial y_{p}} w\left(\boldsymbol{r}_{p}, \boldsymbol{r}_{q}\right) v\left(\boldsymbol{r}_{q}\right) \\
\bar{\gamma}_{x y}\left(\boldsymbol{r}_{p}\right) & =\sum_{q} \frac{\partial}{\partial x_{p}} w\left(\boldsymbol{r}_{p}, \boldsymbol{r}_{q}\right) v\left(\boldsymbol{r}_{q}\right)+\sum_{q} \frac{\partial}{\partial y_{p}} w\left(\boldsymbol{r}_{p}, \boldsymbol{r}_{q}\right) u\left(\boldsymbol{r}_{q}\right)
\end{aligned}
$$

となる。

\section{3 応力}

原子系と連続体とで蓄えられるひずみエネルギーが等しいと いう要請から導く。いま連続体内に任意の領域 $V$ を考学る.

$V$ 内に蓄えられるひずみエネルギー $I_{\mathrm{e}}$ は, 連続体の応力を $\bar{\sigma}_{x}\left(\boldsymbol{r}_{p}\right), \bar{\sigma}_{y}\left(\boldsymbol{r}_{p}\right), \bar{\gamma}_{x y}\left(\boldsymbol{r}_{p}\right)$ とすると

$$
\begin{aligned}
\Pi_{\mathrm{e}}= & \frac{1}{2} \int_{V}\left[\bar{\sigma}_{x}\left(\boldsymbol{r}_{p}\right) \bar{\varepsilon}_{x}\left(\boldsymbol{r}_{p}\right)+\bar{\sigma}_{y}\left(\boldsymbol{r}_{p}\right) \bar{\varepsilon}_{y}\left(\boldsymbol{r}_{p}\right)\right. \\
& \left.+\bar{\tau}_{x y}\left(\boldsymbol{r}_{p}\right) \bar{\gamma}_{x y}\left(\boldsymbol{r}_{p}\right)\right] \mathrm{d} \boldsymbol{r}_{p}
\end{aligned}
$$

であるから，式 (6)，(7)，(8) を代入し，式 (3)，(4)を使うと

$$
\begin{aligned}
\Pi_{\mathrm{e}}= & \frac{1}{2} \int_{V} u\left(\boldsymbol{r}_{q}\right)\left[\int_{\Omega} \frac{\partial w}{\partial x_{q}} \bar{\sigma}_{x}\left(\boldsymbol{r}_{p}\right) d \boldsymbol{r}_{p}\right. \\
& \left.+\int_{\Omega} \frac{\partial w^{\prime}}{\partial y_{q}} \bar{\tau}_{x y}\left(\boldsymbol{r}_{p}\right) \mathrm{d} \boldsymbol{r}_{p}\right] \mathrm{d} \boldsymbol{r}_{q} \\
& +\frac{1}{2} \int_{V} v\left(\boldsymbol{r}_{q}\right)\left[\int_{\Omega} \frac{\partial w}{\partial x_{q}} \bar{\tau}_{x y}\left(\boldsymbol{r}_{p}\right) \mathrm{d} \boldsymbol{r}_{p}\right. \\
& \left.+\int_{\Omega} \frac{\partial u^{\prime}}{\partial y_{q}} \bar{\sigma}_{y}\left(\boldsymbol{r}_{p}\right) \mathrm{d} \boldsymbol{r}_{p}\right] \mathrm{d} \boldsymbol{r}_{q}
\end{aligned}
$$

を得る．そこで場所 $\boldsymbol{r}_{q}$ にいる原子 $q$ の占有体積 $V_{q}$ に働く体 積力の $x, y$ 各成分を

$$
\begin{aligned}
X\left(\boldsymbol{r}_{p}\right)= & \int_{\Omega} \frac{\partial}{\partial x_{q}} w\left(\boldsymbol{r}_{q}, \boldsymbol{r}_{p}\right) \bar{\sigma}\left(\boldsymbol{r}_{p}\right) \mathrm{d} \boldsymbol{r}_{p} \\
& +\int_{\Omega} \frac{\partial}{\partial y_{q}} w\left(\boldsymbol{r}_{q}, \boldsymbol{r}_{p}\right) \bar{\tau}_{x y}\left(\boldsymbol{r}_{p}\right) \mathrm{d} \boldsymbol{r}_{p} \\
Y\left(\boldsymbol{r}_{q}\right)= & \int_{\Omega} \frac{\partial}{\partial x_{q}} w\left(\boldsymbol{r}_{q}, \boldsymbol{r}_{p}\right) \bar{\tau}_{x y}\left(\boldsymbol{r}_{p}\right) \mathrm{d} \boldsymbol{r}_{p} \\
& +\int_{\Omega} \frac{\partial}{\partial y_{q}} w\left(\boldsymbol{r}_{q}, \boldsymbol{r}_{\mathrm{p}}\right) \bar{\sigma}\left(\boldsymbol{r}_{p}\right) \mathrm{d} \boldsymbol{r}_{p}
\end{aligned}
$$

とすれば，上記の要請が満たされる．そこで体積 $V_{q}$ に働く体 積力 $X\left(\boldsymbol{r}_{q}\right), Y\left(\boldsymbol{r}_{q}\right)$ とこの体積の表面で考えた原子の応力 $\sigma_{x}\left(\boldsymbol{r}_{q}\right), \sigma_{y}\left(\boldsymbol{r}_{q}\right), r_{x y}\left(\boldsymbol{r}_{q}\right)$ との関係式

$$
\left.\begin{array}{c}
X\left(\boldsymbol{r}_{q}\right)=\frac{\partial \sigma_{x}\left(\boldsymbol{r}_{q}\right)}{\partial x_{q}}+\frac{\partial \tau_{x y}\left(\boldsymbol{r}_{q}\right)}{\partial y_{q}} \\
Y\left(\boldsymbol{r}_{q}\right)=\frac{\partial \tau_{x y}\left(\boldsymbol{r}_{q}\right)}{\partial x_{q}}+\frac{\partial \sigma_{y}\left(\boldsymbol{r}_{q}\right)}{\partial y_{q}}
\end{array}\right\}
$$

を式 (10), (11) と比較することにより，応力の変換式

$$
\begin{aligned}
& \sigma_{x}\left(\boldsymbol{r}_{q}\right)=\int_{\Omega} w\left(\boldsymbol{r}_{q}, \boldsymbol{r}_{p}\right) \bar{\sigma}_{x}\left(\boldsymbol{r}_{p}\right) \mathrm{d} \boldsymbol{r}_{p} \\
& \sigma_{y}\left(\boldsymbol{r}_{q}\right)=\int_{\Omega} w\left(\boldsymbol{r}_{q}, \boldsymbol{r}_{p}\right) \bar{\sigma}_{y}\left(\boldsymbol{r}_{p}\right) \mathrm{d} \boldsymbol{r}_{p} \\
& \tau_{x y}\left(\boldsymbol{r}_{q}\right)=\int_{\Omega} w\left(\boldsymbol{r}_{q}, \boldsymbol{r}_{p}\right) \bar{\tau}_{x y}\left(\boldsymbol{r}_{p}\right) \mathrm{d} \boldsymbol{r}_{p}
\end{aligned}
$$

を得る (付録 $\mathrm{A}$ 参照)。式 (13) （15）は非局所弾性論 ${ }^{5 / 6)}$ で用 いられる式と形式的に一致するが，その意味や導出過程は全く 異なる。 また式 (1) と式 (13)〜（15）を比較すればわかるよう に，応力と変位とは互いに双対の関係にあり，変位は原子系か ら, 応力は連続体から与えられている. しかし式 (13)～(15)

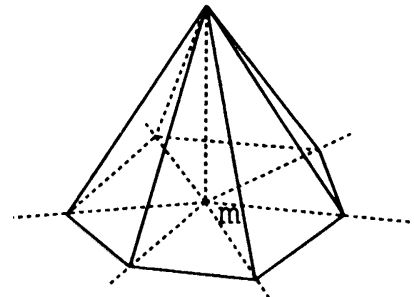

Fig. 1 Pyramidal shape basis function of FEM

を左辺の原子の応力から右辺の連続体の応力への対応と見るこ とも可能であり，原子の応力をボルンの公式）（付録 $\mathrm{A}$ 参照） で測定し，これから式（13）（15）を使って連続体の応力を後 述のよらに逆算することもできる. この場合の連続体応力は原 子間力から直接に算出されることになり，これと式 (6)〜 (8) で得られるひずみとから，ミクロの構成方程式を導出すること も可能になる.

\section{3. 変換の数値計算}

連続体を有限要素法で離散化した場合の, 変換式を具体的に 導出する. いま連続体を三角形 1 次要素で離散化すれば, 離散 化後の諸量へ変換する重み関数は,

$$
w\left(\boldsymbol{r}_{p}, \boldsymbol{r}_{q}\right)=\sum_{m} \sum_{n} w\left(\boldsymbol{r}_{m}, \boldsymbol{r}_{n}\right) H_{m}\left(\boldsymbol{r}_{p}\right) H_{n}\left(\boldsymbol{r}_{q}\right)
$$

となる (付録 B 参照). ただし $\boldsymbol{r}_{m}, \boldsymbol{r}_{n}$ は節点 $m, n$ の位置べク トル, $H_{m}(\boldsymbol{r})$ はいわゆる有限要素法の第 $m$ 基底関数であり, 図 1 のように節点 $m$ 上に高さ 1 の頂点を持つピラミッド形の 関数である. またこのピラミッドの各斜面がいわゆる形状関数 $N_{m}(\boldsymbol{r})$ になる. $w\left(\boldsymbol{r}_{m}, \boldsymbol{r}_{n}\right)$ は展開係数であり, 式 (2)の条件よ り

$$
w\left(\boldsymbol{r}_{m}, \boldsymbol{r}_{n}\right)=\frac{\alpha_{m n}}{\sum_{n \in \Omega_{\mathrm{e}}} \alpha_{m n} S_{n}+\sum_{n \in \bar{\Omega}_{\mathrm{e}}} \alpha_{m n}}
$$

となる、ただし

$$
\begin{aligned}
& \alpha_{m n}=\exp \left[-\frac{\left|\boldsymbol{r}_{m}-\boldsymbol{r}_{n}\right|^{2}}{2 \sigma^{2}}\right] \\
& S_{n}=\sum_{q} H_{n}\left(\boldsymbol{r}_{q}\right)
\end{aligned}
$$

であり， $\Omega_{\mathrm{e}}$ は有限要素近似された領域， $\overline{\mathrm{e}}$ はそれ以外の領域 がもしあればそれ $\left(\Omega=\Omega_{\mathrm{e}} \cup \overline{\Omega_{\mathrm{e}}}\right)$ を表す。

以下，式（16）を前述の変換式に代入する．ただし変位の変 換式はひずみのそれから容易に類推できるから，ひずみと応力 への変換式のみ記す。式（16）を式（6）に代入すれば

$$
\bar{\varepsilon}_{x}\left(\boldsymbol{r}_{p}\right)=\sum_{m} \sum_{n} w\left(\boldsymbol{r}_{m}, \boldsymbol{r}_{n}\right) \frac{\partial H_{m}\left(\boldsymbol{r}_{p}\right)}{\partial x_{p}} \sum_{q} H_{n}\left(\boldsymbol{r}_{q}\right) u\left(\boldsymbol{r}_{q}\right)
$$

式 (19) で $\partial H_{m}\left(\boldsymbol{r}_{p}\right) / \partial x_{p}$ は, 点 $\boldsymbol{r}_{p}$ を内部に含む三角形要素の 節点 $a, b, c$ 以外の $m$ に対し消えること，また $\partial H_{a}\left(\boldsymbol{r}_{p}\right) / \partial x_{p}=$ $\partial N_{a}\left(\boldsymbol{r}_{p}\right) / \partial x_{p}$ などであることに注意すれば

$$
\begin{aligned}
\bar{\varepsilon}_{x}\left(\boldsymbol{r}_{p}\right)= & \frac{\partial N_{a}\left(\boldsymbol{r}_{p}\right)}{\partial x_{p}} \sum_{n} w\left(\boldsymbol{r}_{a}, \boldsymbol{r}_{n}\right) \sum_{q} H_{n}\left(\boldsymbol{r}_{q}\right) u\left(\boldsymbol{r}_{q}\right) \\
& +\frac{\partial N_{b}\left(\boldsymbol{r}_{p}\right)}{\partial x_{p}} \sum_{n} w\left(\boldsymbol{r}_{b}, \boldsymbol{r}_{n}\right) \sum_{q} H_{n}\left(\boldsymbol{r}_{q}\right) u\left(\boldsymbol{r}_{q}\right) \\
& +\frac{\partial N_{c}\left(\boldsymbol{r}_{p}\right)}{\partial x_{p}} \sum_{n} w\left(\boldsymbol{r}_{c}, \boldsymbol{r}_{n}\right) \sum_{q} H_{n}\left(\boldsymbol{r}_{q}\right) u\left(\boldsymbol{r}_{q}\right)
\end{aligned}
$$

となる. $\bar{\varepsilon}_{y}\left(\boldsymbol{r}_{p}\right), \bar{\tau}_{x y}\left(\boldsymbol{r}_{p}\right)$ についても同様である. そこで 


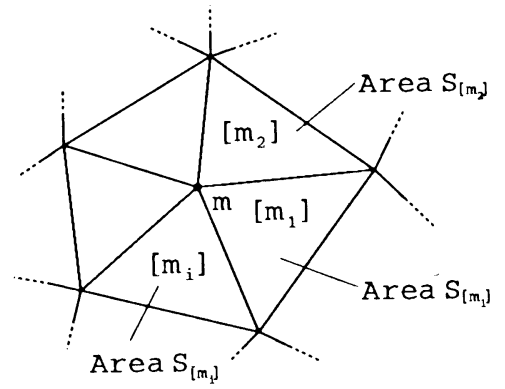

Fig. 2 Finite elements $\left[m_{i}\right]$ covered by the $m$ th basis function (=)elements sharing the node $m$ )

$$
\begin{aligned}
d_{x n}= & \frac{\partial N_{a}\left(\boldsymbol{r}_{p}\right)}{\partial x_{p}} w\left(\boldsymbol{r}_{a}, \boldsymbol{r}_{n}\right)+\frac{\partial N_{b}\left(\boldsymbol{r}_{p}\right)}{\partial x_{p}} w\left(\boldsymbol{r}_{b}, \boldsymbol{r}_{n}\right) \\
& +\frac{\partial N_{c}\left(\boldsymbol{r}_{p}\right)}{\partial x_{p}} w\left(\boldsymbol{r}_{c}, \boldsymbol{r}_{n}\right) \\
d_{y n}= & \frac{\partial N_{a}\left(\boldsymbol{r}_{p}\right)}{\partial y_{p}} w\left(\boldsymbol{r}_{a}, \boldsymbol{r}_{n}\right)+\frac{\partial N_{b}\left(\boldsymbol{r}_{p}\right)}{\partial y_{p}} w\left(\boldsymbol{r}_{b}, \boldsymbol{r}_{n}\right) \\
& +\frac{\partial N_{c}\left(\boldsymbol{r}_{p}\right)}{\partial y_{p}} w\left(\boldsymbol{r}_{c}, \boldsymbol{r}_{n}\right)
\end{aligned}
$$

とすれば, 各要素内のひずみ $\bar{\varepsilon}_{x}\left(\boldsymbol{r}_{p}\right), \bar{\varepsilon}_{y}\left(\boldsymbol{r}_{p}\right), \bar{\tau}_{x y}\left(\boldsymbol{r}_{p}\right)$ が原 子の変位 $u\left(\boldsymbol{r}_{1}\right), u\left(\boldsymbol{r}_{2}\right), \cdots$, によって次のように計算される

$$
\begin{aligned}
& \left\{\begin{array}{l}
\left\{\bar{\varepsilon}_{x}\left(\boldsymbol{r}_{p}\right)\right. \\
\bar{\varepsilon}_{y}\left(\boldsymbol{r}_{p}\right) \\
\bar{\tau}_{x y}\left(\boldsymbol{r}_{p}\right)
\end{array}\right\} \\
& =\left[\begin{array}{ccccc}
d_{x 1} & 0 & d_{x 2} & 0 & \cdots \\
0 & d_{y 1} & 0 & d_{y 2} & \cdots \\
d_{y 1} & d_{x 1} & d_{y 2} & d_{x 2} & \cdots
\end{array}\right]\left[\begin{array}{cccc}
H_{1}\left(\boldsymbol{r}_{1}\right) & 0 & H_{1}\left(\boldsymbol{r}_{2}\right) & \cdots \\
0 & H_{1}\left(\boldsymbol{r}_{1}\right) & 0 & \ldots \\
H_{2}\left(\boldsymbol{r}_{1}\right) & 0 & H_{2}\left(\boldsymbol{r}_{2}\right) & \ldots \\
\ldots & \ldots & \ldots & \ldots
\end{array}\right]\left\{\begin{array}{c}
\boldsymbol{u}\left(\boldsymbol{r}_{1}\right) \\
\boldsymbol{v}\left(\boldsymbol{r}_{1}\right) \\
\boldsymbol{u}\left(\boldsymbol{r}_{2}\right) \\
\vdots
\end{array}\right\}
\end{aligned}
$$

式 (22) 中の $H_{n}\left(\boldsymbol{r}_{q}\right)$ には, 実際には各原子位置 $\boldsymbol{r}_{q}$ を含む要素 の形状関数 $N_{n}\left(\boldsymbol{r}_{q}\right)$ を代入する.

同様に応力についても式 (16) を式 (13) に代入して

$$
\sigma_{x}\left(\boldsymbol{r}_{q}\right)=\sum_{m} \sum_{n} w\left(\boldsymbol{r}_{m}, \boldsymbol{r}_{n}\right) H_{n}\left(\boldsymbol{r}_{q}\right) \int_{\Omega_{\mathbf{e}}} H_{m}\left(\boldsymbol{r}_{p}\right) \bar{\sigma}_{x}\left(\boldsymbol{r}_{p}\right) \mathrm{d} \boldsymbol{r}_{p}
$$

そこで $\boldsymbol{r}_{q}$ を含む要素の節点を $a, b, c$ とし

$$
\begin{aligned}
& c_{q m}\left\{\begin{aligned}
= & N_{a}\left(\boldsymbol{r}_{q}\right) w\left(\boldsymbol{r}_{m}, \boldsymbol{r}_{a}\right)+N_{b}\left(\boldsymbol{r}_{q}\right) w\left(\boldsymbol{r}_{m}, \boldsymbol{r}_{b}\right) \\
& +N_{c}\left(\boldsymbol{r}_{q}\right) w\left(\boldsymbol{r}_{m}, \boldsymbol{r}_{c}\right) \\
= & : \boldsymbol{r}_{q} \in \Omega_{\mathrm{e}} \\
\left.\sigma_{m}, \boldsymbol{r}_{q}\right) \quad & : \boldsymbol{r}_{q} \in \overline{\Omega_{\mathrm{e}}}
\end{aligned}\right. \\
& \sigma_{x m}^{*}=\int_{\Omega_{\mathrm{e}}} H_{m}\left(\boldsymbol{r}_{p}\right) \bar{\sigma}_{x}\left(\boldsymbol{r}_{p}\right) \mathrm{d} \boldsymbol{r}_{p}
\end{aligned}
$$

とすれば, 式 (23) は

$$
\sigma_{x}\left(\boldsymbol{r}_{q}\right)=\sum_{m} c_{q m} \sigma_{x m}^{*}
$$

となる. $\sigma_{y}\left(\boldsymbol{r}_{q}\right), \tau_{x y}\left(\boldsymbol{r}_{q}\right)$ についても同様である. 式 (25)の $\sigma_{x m}^{*}$ は, 図 2 のように節点 $m$ を共有する要素 $\left[m_{i}\right](i=1,2, \cdots)$ の面積を $S_{\left[m_{i}\right]}$, 要素内の一定応力を $\bar{\sigma}_{x\left[m_{i}\right]}$ とすれば

$$
\sigma_{x m}^{*}=\sum_{i} \frac{1}{3} S_{\left[m_{i}\right]} \bar{\sigma}_{x\left[m_{i}\right]}
$$

となるから，最終的に原子の応力と要素内応力とを結び付ける 関係式は

$$
\left\{\begin{array}{c}
\sigma_{x}\left(\boldsymbol{r}_{1}\right) \\
\sigma_{x}\left(\boldsymbol{r}_{2}\right) \\
\vdots
\end{array}\right\}=\frac{1}{3}\left[\begin{array}{ccc}
c_{11} & c_{12} & \cdots \\
c_{21} & c_{22} & \cdots \\
\cdots & \cdots
\end{array}\right\}\left[\begin{array}{ccc}
S_{11} & S_{12} & \cdots \\
S_{21} & S_{22} & \cdots \\
\cdots \cdots & \cdots
\end{array}\right]\left\{\begin{array}{c}
\bar{\sigma}_{[1]} \\
\bar{\sigma}_{[2]} \\
\vdots
\end{array}\right\}
$$

Tool (Diamond)

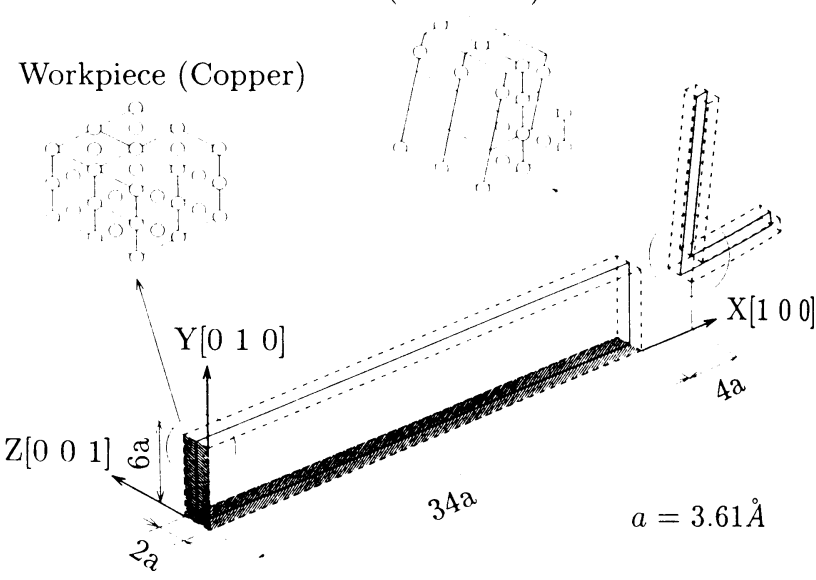

Fig. 3 Setup of atomic-model-based simulation of nanoscale cutting

となる。ただし式（28）中の $S_{m i}$ は

$$
S_{m i}\left\{\begin{array}{l}
=S_{|i|}: \text { 節点 } m \text { が装素 }[i] \text { に含まれる特 } \\
=0 \text { : それ以外 }
\end{array}\right.
$$

とする. 式(28)を

$$
\left\{\sigma_{x}\right\}=[G]\left\{\bar{\sigma}_{x}\right\}
$$

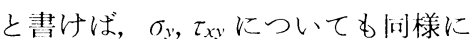

$$
\begin{aligned}
& \left\{\sigma_{y}\right\}=[G]\left\{\bar{\sigma}_{y}\right\} \\
& \left\{\tau_{x y}\right\}=[G]\left\{\bar{\tau}_{x y}\right\}
\end{aligned}
$$

となる. 式 $(30)$ （32）は，連続体の忍力 $\left\{\bar{\sigma}_{x}\right\},\left\{\bar{\sigma}_{y}\right\},\left\{\bar{\tau}_{x y}\right\}$ か ら原子の忘力 $\left\{\sigma_{x}\right\},\left\{\sigma_{y}\right\},\left\{\tau_{x y}\right\}$ への变換として使ら場合は何ら問 題ない，逆に原子の忍力を知って連続体の応力を求める場合

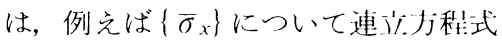

$$
\left([G]^{\mathrm{T}}[G]\right)\left\{\bar{\sigma}_{x}\right\}=\left[G^{\mathrm{T}}\right]^{\mathrm{T}}\left\{\sigma_{x}\right\}
$$

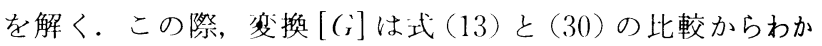
るよらに平均化操作を表すため, 式 (33)の係数マトリクス

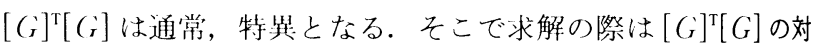
角成分に適当な让数を加えて則化する

\section{4. ナノスケール切削への適用}

計算機実験に使用した原子系划削モデルを図 3 に示す，被削 材は銅単結晶, 1具はダイヤモンド㴊体結晶とし, 犾先丸るは 考えていない，被削材のサイズを鉰単結晶の格子定数を $a$ と して为中に亦寸。被削材は斜線部を沾定している。原子間术テ ンシャルは，銅原子間に多体ポテンシャルであるEAM (Embedded-Atom-Method) ${ }^{9)}$ を，銅炭素原子閪にモースポテ ンシャル1を使った。切削は $Z$ 方们に溒期境界条件を導入し て2次元切削とし，工，具の微小前進ごとに被削材原子の安定配 列を計算する純静的手法によって行った。切削较験の結果を有 限要素モデルのそれに变換する手続きを図 4 亿示す。亦ず基準 とする切削途中の状態に㘠 4 (a) のように有限要素メッシュを かぶせ，境界線に汾って切り沙す。次には具を所定の量だけ前 進させて原子系の切削を進行させる。この㭙，既述の式 (1), （16）を使って各節点の変位をその周用の原子変位から計算し, 図 4 (b)のように有限要素モデルを変形させる. 各要素内のひ ずみは式 (22) で，伈力は原子圭力をボルンの公式で求め，こ れを式 (33)の有过に代入して計算する.

得られた相当ひずみ堌分の分布を図 5 (a)，(b)に示す。困中 には，堌分計算に使った1，具基準位置と増分前進量も示寸。平 
FEM mesh

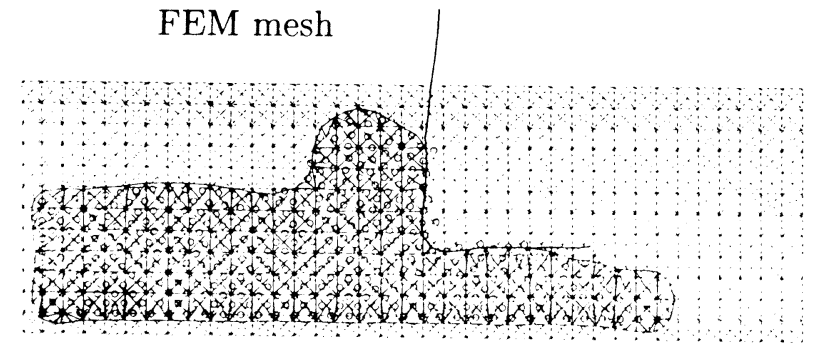

(a) Mesh covering and trimming

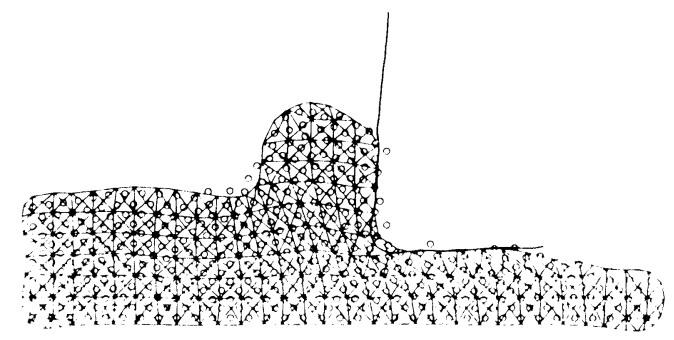

(b) Mesh deformation

Fig. 4 Procedure for obtaining equivalent finite element deformation

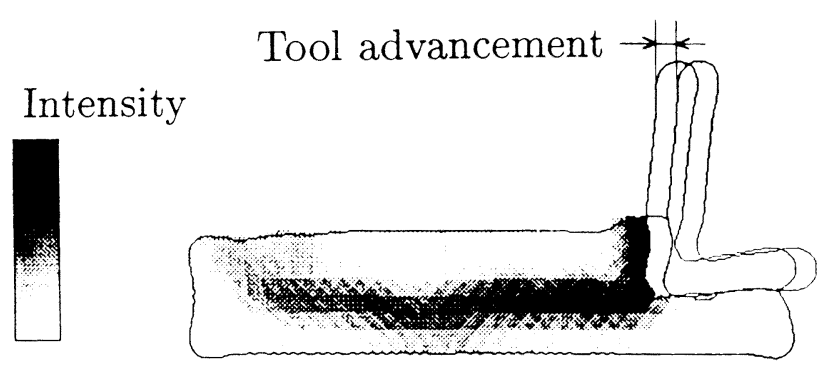

(a) Early stage of cutting

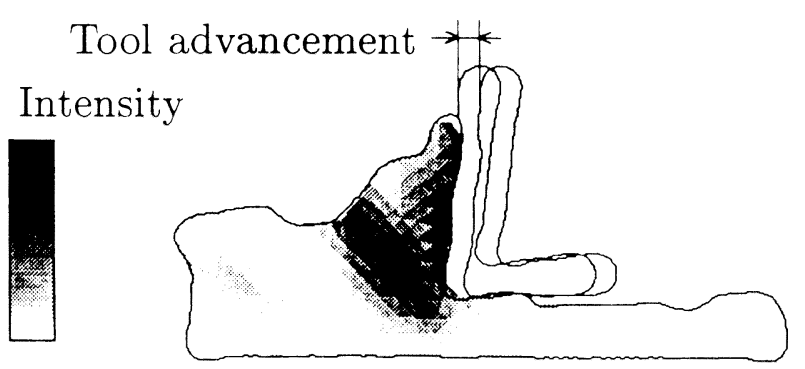

(b) Developed stage of cutting

Fig. 5 Effective incremental strain distribution

勾化のパラメータはのー゙としている。此較的切㴥初期の状態 である図5(a)を見ると，芯の濃い尚ひずみ領域が1具すくい 面上:拉よび丁具义先からかなり前うに延びていることがわか る.これらのひず蛙いずれも主としてせん断によるものであ

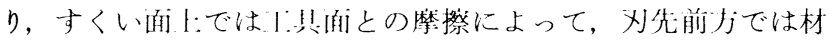
料表層部が切㴥うj向にH:維されていることによって生じてい る.切りくずとしての材料の盛、がりがこの段階ではほとんど 見られないのに，来切测裴風部がこの上うに大きな縮変形を 示寸のは結昆先端が洞定されているためと, ミクロ特有の表面 張力の影響である。四 5(b) は, これより切削が進行した状態 での相当ひず文增分を示す。この段階ではいかわる一次せん断

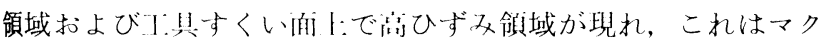

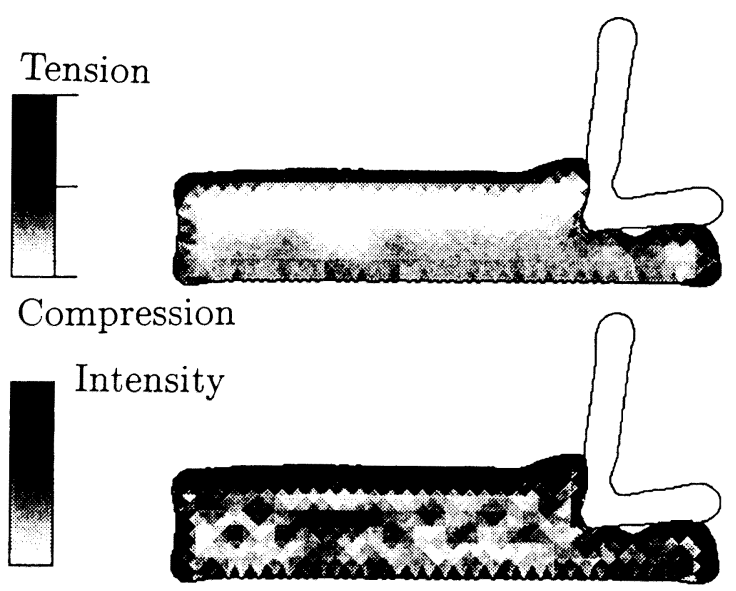

(a) Early stage of cutting

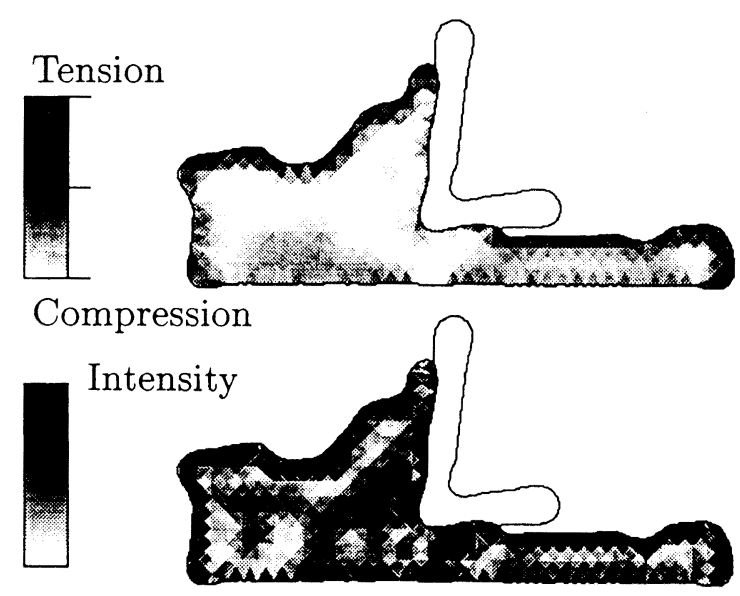

(b) Developed stage of cutting

Fig. 6 Maximum tensile/compressive stress distribution (upper) and maximum shear stress distribution (lower)

口切削のそれに注涪対応している。一方，図 5 に対応する応力 分布を図 6 (a)，(b) に示す。ただし応力は增分ではなく, 図 5 の工具前進位置での值である. 平均化のパラメータは $\sigma=a$, $[G]^{\mathrm{T}}[G]$ の対角成分に加光る值は 1.0 とした。 また図6(a), (b)では，それぞれ、側に最大引張り/圧縮応力分布を，下側 に最大せん断応力分布を濃淡表現により示している. 図 6 (a) の上側の図を見ると, 被削材自由表面に表面張力が働いている こと，末た工具前方の未切削部には強い王縮応力が作用してい ることがわかる。一方，図6 (a) 下側の図では, 被削材自由面 に沿って表面張力に起因した強いせん断応力が働いているこ と，また図 5 (a)でせん断ひずみが集中している部分に，わず か飞応力の高い部分が認められることがわかる。 これに対し図 6(b) を見ると，上側の図では工具咸先付近から前方に向かっ て強い王縮応力が働いているのは前と同様であるが，下側のせ ん断応力の分布では, 工具刚先から逃げ面とすくい面に沿って 高い值が現れているすのの, 図 5 (b) でせん断ひずみの集中が 見られた一次せん断域ではマク口切削の上らなせん断応力の集 中が見られない。充たこの一次せん断域での応力值は 1 3 GPa 程度であり, これはマク口切削でのせん断面せん断応力 よりは高いが，銅結晶の理論せん断応力 $5 \sim 6 \mathrm{GPa}$ 上り低い。 この事実は, ナノスケール切削に打ける切りくず生成が結晶面 での単純すべりによらず, より複雑なメカニズムによってより 
低い応力で行われていることを示す．またひずみの分布と応力 の分布が詨応していないのは，塑性ひずみすなわち原子配列の 乱れによって材料定数そのものが不均一に変わるためであると 言え，これは例えば一次せん断域で発熱が仮になくても材料が 軟化し得ることを示唆している点で興味深い. 以上よりナノス ケール切削の力学はマク口切削のそれと大きく異なること,さ らにこのようなミクロ特有の現象を調べるには，応力とひずみ を各々独立に評価できる本研究の手法が不可欠であることがお かる.

\section{5. 結 論}

（1）平均化の概念を使い，原子系と連続体との力学量の変 換法を提案した．この変換は両モデル間でひずみェネル ギーを保存する。

（2）提案した手法に基づき，原子系から応力やひずみを算 出する具体的な数値計算法を示した.

（3）原子モデルによるナノスケール切削の計算機実験結果 に本手法を適用したところ，ひず夕分布はマク口划削と大 差ないが，応力分布はマク口のそれと大きく異なることが 見い出された。

\section{謝辞}

本研究は(株)松浦機械製作所の全面的な支援を受け行われ た。 また研究を進める上で，北川浩阪大教授を始めとする日本 機械学会分子動力学研究分科会の諸氏との討論が役立った。な 㧍数值計算の一部は本学 4 年生（当時）河野朗君が行った。終 わりに, 本研究は一部, 文部省科学研究費補助金（一般研究 (C)）の交付を受けたことを付記する.

\section{[付録 A]}

Irving \& Kirkwood ${ }^{10)}$ によれば， 2 体ポテンシャル $\phi$ の作用 する原子系内の点 $\boldsymbol{r}_{p}$ で定義される応力テンソル $\overline{\boldsymbol{\sigma}}\left(\boldsymbol{r}_{p}\right)$ は, $\boldsymbol{R}$ を原子対を結ぶベクトル， $\alpha$ をスカラ， $\rho^{(2)}(\boldsymbol{r}, \boldsymbol{r}+\boldsymbol{R})$ を原子 対の片方が点 $\boldsymbol{r}$ に, 他方が $\boldsymbol{r}+\boldsymbol{R}$ にいる 2 体確率密度関数と して

$$
\begin{aligned}
\overline{\boldsymbol{\sigma}}\left(\boldsymbol{r}_{p}\right)= & \frac{1}{2} \int \frac{\boldsymbol{R} \boldsymbol{R}^{\mathrm{T}}}{|\boldsymbol{R}|} \frac{\mathrm{d} \phi(|\boldsymbol{R}|)}{\mathrm{d}|\boldsymbol{R}|} \\
& \times\left[\int_{0}^{1} \rho^{(2)}\left(\boldsymbol{r}_{p}-\alpha \boldsymbol{R}, \boldsymbol{r}_{p}-\alpha \boldsymbol{R}+\boldsymbol{R}\right) \mathrm{d} \alpha\right] \mathrm{d} \boldsymbol{R}
\end{aligned}
$$

で与えられる。彼らは明確に述べていないが， $\boldsymbol{r}_{p}$ として原子 間位置を考学る場合，明らかに連続体の概念が原子系の1:に重 ねられてそれが可能になって打り，この時の式(A-1) は連続 体応力を与える。 本た式 (A-1) 右辺中の

$$
\widetilde{\rho}^{(2)}\left(\boldsymbol{r}_{p}, \boldsymbol{r}_{p}+\boldsymbol{R}\right)=\int_{0}^{1} \rho^{(2)}\left(\boldsymbol{r}_{p}-\alpha \boldsymbol{R}, \boldsymbol{r}_{p}-\alpha \boldsymbol{R}+\boldsymbol{R}\right) \mathrm{d} \alpha
$$

は，積分演算によって $\rho^{(2)}$ の第 1 変数に関する確率を 1 にした もの，すなわち “任意の原子 1 個を場所 $\boldsymbol{r}_{p}$ で捕ら光，この原 子から見た相手原子の存在確率密度”を表す。一方，原子の応 力は $\boldsymbol{r}_{p}$ を原子位置 $\boldsymbol{r}_{q}$ に一致させて最初から $\widetilde{\rho}^{(2)}\left(\boldsymbol{r}_{q}, \boldsymbol{r}_{q}+\boldsymbol{R}\right)$ として考光，これを式 (A-1) に代入した

$$
\boldsymbol{\sigma}\left(\boldsymbol{r}_{q}\right)=\frac{1}{2} \int \frac{\boldsymbol{R} \boldsymbol{R}^{\mathrm{T}}}{|\boldsymbol{R}|} \frac{\mathrm{d} \phi(|\boldsymbol{R}|)}{\mathrm{d}|\boldsymbol{R}|} \widetilde{\rho}^{(2)}\left(\boldsymbol{r}_{q}, \boldsymbol{r}_{q}+\boldsymbol{R}\right) \mathrm{d} \boldsymbol{R}
$$

とすればよい。これはボルンの公式の一般形に泀かならない。 次に式 (A-1) と（A-3）の関係を導くために $N$ 個の原子を含 む系の配置空間（相空間の座標部分）を考え，その確率分布関
数を $f\left(\boldsymbol{r}_{1}, \boldsymbol{r}_{2}, \cdots, \boldsymbol{r}_{N}\right)$ とする. この時, デルタ関数を $\delta(\boldsymbol{r})$ と して

$$
f_{q}(\boldsymbol{r})=\int \delta\left(\boldsymbol{r}_{q}-\boldsymbol{r}\right) f\left(\boldsymbol{r}_{1}, \boldsymbol{r}_{2}, \cdots, \boldsymbol{r}_{N}\right) \mathrm{d} \boldsymbol{r}_{1} \mathrm{~d} \boldsymbol{r}_{2} \cdots \mathrm{d} \boldsymbol{r}_{N}
$$

は場所 $\boldsymbol{r}$ に原子qがいる確摔を表す。したがって

$$
f_{q}^{*}(\boldsymbol{r})=\frac{f_{q}(\boldsymbol{r})}{\sum_{q=1}^{N} f_{q}(\boldsymbol{r})}
$$

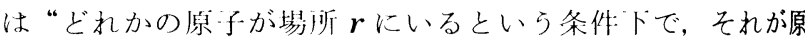
子 qである確摔”になる。 そこで式 (1)における重文関数が

$$
w^{\prime}\left(\boldsymbol{r}_{p}, \boldsymbol{r}_{q}\right)=f_{q}^{*}\left(\boldsymbol{r}_{p}\right)
$$

であるとすれば，これは式（2）の条件を満たす。また式（A1)，(A-2)，(A-6)を本文の式（13）（15）の不辺に代入すれば

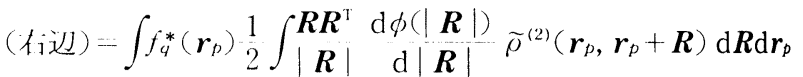

$$
\begin{aligned}
& =\frac{1}{2} \int \frac{\boldsymbol{R}^{\mathrm{T}}}{|\boldsymbol{R}|} \frac{\mathrm{d} \phi(|\boldsymbol{R}|)}{\mathrm{d}|\boldsymbol{R}|} \\
& \times\left[\int f_{q}^{*}\left(\boldsymbol{r}_{p}\right) \tilde{\rho}^{(2)}\left(\boldsymbol{r}_{p}, \boldsymbol{r}_{p}+\boldsymbol{R}\right) \mathrm{d} \boldsymbol{r}_{p}\right] \mathrm{d} \boldsymbol{R}
\end{aligned}
$$

式 (A 7) で， [ ]内は $f_{q}^{*}\left(\boldsymbol{r}_{p}\right)$ と $\widetilde{\rho}^{(2)}\left(\boldsymbol{r}_{p}, \boldsymbol{r}_{p}+\boldsymbol{R}\right)$ の既述の意 味から明らかなように，原子、から見た相于原子の存在確率 密度 $\widetilde{\rho}^{(2)}\left(\boldsymbol{r}_{q}, \boldsymbol{r}_{q}+\boldsymbol{R}\right)$ になる。したがって式 $(\mathrm{A}-7)$ は (A-3) に一致し，連続体応力と原子応力の関係式 (13) （15) が立証 された。な挆式 $(\mathrm{A}-3)$ のボルンの公式で，原子系が結晶構造 であれば $\widetilde{\rho}^{(2)}\left(\boldsymbol{r}_{q}, \boldsymbol{r}_{q}+\boldsymbol{R}\right)$ は原子位㯰にピークを持つデル夕関 数となり，良く知られた成分表示

$$
\begin{aligned}
& \sigma_{x}\left(\boldsymbol{r}_{q}\right)=\frac{1}{2 V_{q}} \sum_{s} \frac{\mathrm{d} \phi\left(r_{q s}\right)}{\mathrm{d} r_{q s}} \frac{x_{q s}{ }^{2}}{r_{q s}} \\
& \sigma_{y}\left(\boldsymbol{r}_{q}\right)=\frac{1}{2 V_{q}} \sum_{s} \frac{\mathrm{d} \phi\left(r_{q s}\right)}{\mathrm{d} r_{q s}} \frac{y_{q s}{ }^{2}}{r_{q s}}
\end{aligned}
$$

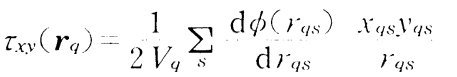

が得られる。ただし $V_{q}$ は原子 $q$ の占有体積， $r_{q s}=\left|\boldsymbol{R}_{q s}\right|$ は原 子 $q \cdots s$ 間の趾離, $x_{4 s}, y_{q s}$ はr $r_{4 s}$ の $x, y$ 成分である.

\section{[付録 B]}

要素分割後の節点の位置べクトルを $\boldsymbol{r}_{i}, \boldsymbol{r}_{j}, \boldsymbol{r}_{k}, \boldsymbol{r}_{m}, \boldsymbol{r}_{n}$ などと 玄る。任意の焦 $\boldsymbol{r}_{p}$ の連続体変位 $\overline{\boldsymbol{u}}\left(\boldsymbol{r}_{p}\right)$ は， $\boldsymbol{r}_{p}$ を含む三角形 要素の節点変位 $\overline{\boldsymbol{u}}_{i}, \overline{\boldsymbol{u}}_{j}, \overline{\boldsymbol{u}}_{k}$ を形状䁖数 $N_{i}, N_{j}, N_{k}$ により補間 して

$$
\overline{\boldsymbol{u}}\left(\boldsymbol{r}_{p}\right)=N_{i}\left(\boldsymbol{r}_{p}\right) \overline{\boldsymbol{u}}_{i}+N_{j}\left(\boldsymbol{r}_{p}\right) \overline{\boldsymbol{u}}_{k}+N_{k}\left(\boldsymbol{r}_{p}\right) \overline{\boldsymbol{u}}_{k}
$$

と表現される。これを式（1）を使って書けば

$$
\begin{aligned}
\int_{\Omega} w\left(\boldsymbol{r}_{p}, \boldsymbol{r}_{q}\right) \boldsymbol{u}\left(\boldsymbol{r}_{q}\right) \mathrm{d} \boldsymbol{r}_{q}= & \int_{\Omega} N_{i}\left(\boldsymbol{r}_{p}\right) w^{\prime}\left(\boldsymbol{r}_{i}, \boldsymbol{r}_{q}\right) \boldsymbol{u}\left(\boldsymbol{r}_{q}\right) \mathrm{d} \boldsymbol{r}_{q} \\
& +\int_{\Omega 2} N_{j}\left(\boldsymbol{r}_{p}\right) w\left(\boldsymbol{r}_{j}, \boldsymbol{r}_{q}\right) \boldsymbol{u}\left(\boldsymbol{r}_{q}\right) \mathrm{d} \boldsymbol{r}_{q} \\
& +\int_{\Omega} N_{k}\left(\boldsymbol{r}_{p}\right) w\left(\boldsymbol{r}_{k}, \boldsymbol{r}_{q}\right) \boldsymbol{u}\left(\boldsymbol{r}_{q}\right) \mathrm{d} \boldsymbol{r}_{q}
\end{aligned}
$$

となるが, $\boldsymbol{u}\left(\boldsymbol{r}_{q}\right)$ としては任意の分布が叮能であるから

$$
\begin{aligned}
w\left(\boldsymbol{r}_{p}, \boldsymbol{r}_{q}\right)= & N_{i}\left(\boldsymbol{r}_{p}\right) w\left(\boldsymbol{r}_{i}, \boldsymbol{r}_{q}\right)+N_{j}\left(\boldsymbol{r}_{p}\right) w\left(\boldsymbol{r}_{j}, \boldsymbol{r}_{q}\right) \\
& +N_{k}\left(\boldsymbol{r}_{p}\right) w\left(\boldsymbol{r}_{k}, \boldsymbol{r}_{q}\right)
\end{aligned}
$$

が成り立つ。ころで式（B-1）は，変位の基成関数 $H_{m}(\boldsymbol{r}) に$ よる展開

$$
\overline{\boldsymbol{u}}\left(\boldsymbol{r}_{p}\right)=\sum_{m} \overline{\boldsymbol{u}}_{m} H_{m}\left(\boldsymbol{r}_{p}\right)
$$

の別表現であるから，式（B-3）もこれに対心させると

$$
w\left(\boldsymbol{r}_{p}, \boldsymbol{r}_{q}\right)=\sum_{m} w\left(\boldsymbol{r}_{m}, \boldsymbol{r}_{q}\right) H_{m}\left(\boldsymbol{r}_{p}\right)
$$




$$
\begin{aligned}
& \text { となる. 更に式 }(3),(\mathrm{B}-3) \text { より } \\
& \begin{aligned}
w\left(\boldsymbol{r}_{p}, \boldsymbol{r}_{q}\right)= & w\left(\boldsymbol{r}_{q}, \boldsymbol{r}_{p}\right) \\
= & N_{i}\left(\boldsymbol{r}_{q}\right) w\left(\boldsymbol{r}_{i}, \boldsymbol{r}_{p}\right)+N_{j}\left(\boldsymbol{r}_{q}\right) w\left(\boldsymbol{r}_{j}, \boldsymbol{r}_{p}\right) \\
& +N_{k}\left(\boldsymbol{r}_{q}\right) w\left(\boldsymbol{r}_{k}, \boldsymbol{r}_{p}\right)
\end{aligned} \\
& \text { も言えるから, } \boldsymbol{r}_{p} \rightarrow \boldsymbol{r}_{m} \text { とすれば } \\
& \qquad\left(\boldsymbol{r}_{m}, \boldsymbol{r}_{q}\right)=\sum_{n} w\left(\boldsymbol{r}_{m}, \boldsymbol{r}_{n}\right) H_{n}\left(\boldsymbol{r}_{q}\right)
\end{aligned}
$$

ただし を式 (B-5) に代入すれば，本文の式

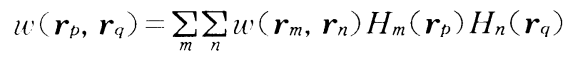

を得る。重み係数 $w\left(\boldsymbol{r}_{m}, \boldsymbol{r}_{n}\right)$ に関する条件は, 式 (16)で $\boldsymbol{r}_{p} \rightarrow$ $r_{m}$ とし, 式 (2) より

$$
\sum_{n} u\left(\boldsymbol{r}_{m}, \boldsymbol{r}_{n}\right) S_{n}=1
$$

式 (B-7) を変形して

$$
w\left(\boldsymbol{r}_{m}, \boldsymbol{r}_{m}\right) \sum_{n} \alpha_{m n} S_{n}=1
$$

とし， $\alpha_{m n}=w\left(\boldsymbol{r}_{m}, \boldsymbol{r}_{n}\right) / w\left(\boldsymbol{r}_{m}, \boldsymbol{r}_{m}\right)$ および $S_{n}$ を式 (18)で与党 れば, 式 (17) を得る。ただし式 (17) では，有限要素近似され ていない領域の存在も考慮した.

\section{参 考 文 献}

1）稲村豊四郎, 鈴木裕幸, 武澤伸浩：銅とダイヤモンドの原子配列モ デルによる計算機内での切削実験，精密工学会誌，56，8（1990） 1480 .

2) S. Shimada, N. Ikawa, G. Ohmori, H. Tanaka and J. Uchikoshi : Molecular Dynamic Analysis as Compared with Experimental Results of Micromachining, Ann. CIRP, 41, 1, (1992) 117.

3) W. G. Hoover et al. : Molecular Dynamics Modeling of Indentation and Cutting, Thrust Area Report FY 90, LLNL, (1991).

4) M. Mullins and M. A. Dokainish : Simulation of the (001) Plane Crack in $\alpha$-Iron Employing a New Boundary Scheme, Phil. Mag., A, 46, 5, (1982) 771

5) S. Kohlhoff, S. Schmauder and P. Gumbsch : A New Method for Coupled Elastic-Atomistic Modeling, in Large Atomistic Simulation of Materials - Beyond Pair Potentials, V. Vitek and D. J. Srolovitz eds, Plenum Press, New York and London, (1988) 411.

6) A. C. Eringen : On Differential Equations of Nonlocal Elasticity and Solutions of Screw Dislocation and Surface Waves, J. Appl. Phys., 54, 9, (1983) 4703.

7) M. Born and K. Huang: Dynamical Theory of Crystal Lattices, Clarendon Press, Oxford, (1954) 129.

8）岡本良夫：逆問題とその解き方，オーム社（1992）.

9) M. S. Daw and M. I. Baskes : Embedded-Atom-Method : Derivation and Application to Impurities, Surface, and Other Defects in Metals, Phys. Rev., B, 29, 12, (1984) 6443.

10) J. H. Irving, J. Kirkwood: The Statistical Mechanical Theory of Transport Processes, IV The Equations of Hydrodynamics, J. Chem. Phys., 18, 6, (1950) 817. 